\title{
Assessment of cell viability in four novel endodontic sealers
}

\author{
Vassiliki Taraslia ${ }^{1}$, Ema Anastasiadou ${ }^{1}$, Christina Lignou ${ }^{1}$, Georgios Keratiotis ${ }^{2}$, \\ Anastasia Agrafioti ${ }^{2}$, Evangelos G. Kontakiotis ${ }^{2}$
}

Correspondence: Dr. Evangelos G. Kontakiotis

Email: ekontak@dent.uoa.gr

\author{
'Department of Genetics and Gene Therapy, Biomedica \\ Research Foundation of the Academy of Athens, \\ Athens, Greece, \\ 2Department of Endodontics, School of Dentistry, \\ National and Kapodistrian University of Athens, \\ Athens, Greece
}

\section{ABSTRACT}

Objective: The aim of this study was to evaluate the viability of human periodontal ligament (PDL) cells on MTA-Fillapex, GuttaFlow 2, TotalFill Sealer, and BioRoot ${ }^{\mathrm{TM}}$ RCS in comparison to conventional epoxy resin-based (AH Plus) and zinc oxide-eugenol-based (Roth's 801) sealers. Materials and Methods: Sealers were divided into two groups, and five coverslips for each material per group were prepared. In the first group, PDLs were added immediately after the preparation of sealers (Fresh Group), and in the second, PDLs were added after $24 \mathrm{~h}$. PDLs were cultured for $72 \mathrm{~h}$ and afterward, counted using standard hematocytometry. A Mann-Whitney U-test and Kruskal-Wallis test were used for the statistical analysis. The level of significance was set at $5 \%$. Furthermore, cell morphology was assessed by confocal microscopy. Results: The number of viable cells for the 24 h-set groups was higher than the freshly mixed in all sealers except Roth's 801. In both groups, GuttaFlow 2 presented the highest number of viable cells. In a descending order of cells' survival, TotalFill, BioRoot, and MTA-Fillapex are following and the conventional sealers, AH Plus and Roth's 801, seem not to exhibit the biological properties of the others. Cells grown on GuttaFlow 2, TotalFill, and BioRoot were observed to be well-formed. In contrast, MTA-Fillapex exhibited untypical morphology. No cells were detected on the surfaces of AH Plus, as well as Roth's 801. Conclusions: All novel sealers presented increased cell viability in comparison to conventional sealers. GuttaFlow 2 exhibited the highest cell viability.

Key words: Cell morphology, cells viability, sealers

\section{INTRODUCTION}

During the final stage of endodontic treatment, root canal filling materials and especially endodontic sealers may contact periradicular tissues and potentially toxic components may leach from the canal space over time. Endodontic materials should stimulate repair or be biologically neutral to promote healing. ${ }^{[1]}$ Therefore, they should not be cytotoxic, so as not to negatively influence the viability of cells

\begin{tabular}{|l|l|}
\hline \multicolumn{3}{|c|}{ Access this article online } \\
\hline Quick Response Code: \\
\hline
\end{tabular}

and cause cell death by apoptosis or necrosis. ${ }^{[2]}$ The study of sealer biocompatibility is very important to help the clinician select sealers that would minimize the potential incidence of unwanted local and/or systemic side effects. ${ }^{[3]}$

Recently, four novel endodontic sealers were introduced, namely, mineral trioxide aggregate (MTA)

This is an open access journal, and articles are distributed under the terms of the Creative Commons Attribution-NonCommercial-ShareAlike 4.0 License, which allows others to remix, tweak, and build upon the work non-commercially, as long as appropriate credit is given and the new creations are licensed under the identical terms.

For reprints contact: reprints@medknow.com

How to cite this article: Taraslia V, Anastasiadou E, Lignou C, Keratiotis G, Agrafioti A, Kontakiotis EG. Assessment of cell viability in four novel endodontic sealers. Eur J Dent 2018;12:287-91.

DOI: 10.4103/ejd.ejd_9_18 
Fillapex (Angelus Soluções Odontológicas, Londrina, PR, Brazil), GuttaFlow 2 (Coltène/Whaledent, Langenau, Germany), TotalFill BC Sealer (FKG, Dentaire SA, La Chaux-de-Fonds, Switzerland), and Bioroot ${ }^{\mathrm{TM}}$ RCS (BR, Septodont, France). MTA has attracted considerable attention because of its excellent biocompatibility, sealing ability, and antimicrobial properties. ${ }^{[4,5]}$ For these reasons, newer formulations of MTA as a root canal sealer, such as MTA Fillapex, have been developed in an attempt to expand its range of applications. The chemical composition of MTA Fillapex consists of two main components: MTA and salicylate resin. ${ }^{[6]}$ Due to its MTA content, MTA Fillapex is biocompatible and stimulates mineralization. ${ }^{[7]}$

GuttaFlow 2 is a new formulation of GuttaFlow. It consists of similar components but in altered proportions. It is a cold flowable silicone-based sealer that is triturated and consists of guttapercha powder into a silicone matrix (polydimethylsiloxane) and nanosilver particles. It comes in a unidose capsule and is injected after mixing. ${ }^{[8,9]}$ GuttaFlow 2 demonstrates very promising properties due to its insolubility, biocompatibility, postsetting expansion, great fluidity, and ability for providing a thin film of sealer, and hence greater adhesion with the dentinal wall. ${ }^{[10,11,12]}$ However, GuttaFlow, the previous version of this sealer, is reported to display low contact angle. ${ }^{[11]}$ Furthermore, the previous studies of GuttaFlow exhibited low toxicity profiles when compared with other sealers both in vitro and in vivo. $[8,10,12,13]$

EndoSequence BC Sealer, also known as TotalFill BC Sealer in Europe, is a new premixed, injectable bioceramic root canal sealer. Its major components include tricalcium silicate, dicalcium silicate, calcium phosphates, colloidal silica, calcium hydroxide, zirconium oxide, and thickening agents. It utilizes the moisture within the dentinal tubules following canal irrigation to initiate and complete the setting reaction. ${ }^{[12]}$ Moreover, it demonstrates one of the strongest antimicrobial activities among endodontic sealers. ${ }^{[14]}$

BioRoot ${ }^{\mathrm{TM}} \mathrm{RCS}$ is a bioactive mineral root canal sealer based on innovative mineral microaggregate chemistry named "active biosilicate technology." [15] It is a sealer without any sign of resin or eugenol, which makes it different from conventional root canal sealers. An aqueous solution of calcium chloride and excipients is mixed with a powder based on tricalcium silicate and zirconium oxide. It allows $\mathrm{pH}$ values to increase over 11 and has hydrophilic properties. ${ }^{[15]}$ According to some studies Bioroot ${ }^{\mathrm{TM}} \mathrm{RCS}$ has higher bioactivity in comparison to conventional zinc oxide-eugenol sealers on human periodontal ligament (PDL) cells ${ }^{[16]}$ and is also less cytotoxic at pulpal stem cells. ${ }^{[15]}$

In vitro analysis regarding the probable cytotoxic effects of new endodontic sealers is essential to determine the potential for an adverse event of a new sealer compared with previously studied endodontic sealers. Based on the current literature, there are few studies evaluating the cytotoxicity of MTA Fillapex, GuttaFlow 2, BC sealers, and Bioroot ${ }^{\mathrm{TM}}$ RCS. ${ }^{[15-18]}$ The purpose of this study was to evaluate the viability of PDLs cells on MTA Fillapex, GuttaFlow 2, TotalFill Sealer, and BioRoot ${ }^{\mathrm{TM}}$ RCS in comparison to conventional epoxy resin-based (AH Plus) and zinc oxide-eugenol-based (Roth's 801) sealers.

\section{MATERIALS AND METHODS}

\section{Cell culture}

PDL cells were provided by ProCell, Biotechnological Application SA (Athens, Greece). The cells were cultured in Dulbecco's Modified Eagle's Medium (DMEM; Gibco, Glasgow, UK), supplemented with streptomycin, penicillin, and L-glutamine and complemented with $10 \%$ heat-inactivated fetal bovine serum (FBS, Biowest) at $37^{\circ} \mathrm{C}$ in a $5 \% \mathrm{CO}_{2}$ humidified incubator. Cells were used between third and fifth passage. Five independent experiments were performed to ensure reproducibility.

\section{Cell viability assays}

Cell viability assays were performed using transwells (Costar Transwell; Corning Inc., Corning, NY, USA). The materials tested in this study were MTA Fillapex, GuttaFlow 2, BC sealer, Bioroot ${ }^{\mathrm{TM}}$ RCS, AHPlus (Dentsply DeTrey, Konstanz, Germany) and Roth's 801(Roth's Pharmacy-Chicago). The sealers were prepared under aseptic conditions according to the manufacturer's instructions and were immediately placed on a $13 \mathrm{~mm}$ coverslip. These sealers were divided into two groups. In the first group, PDL cells were added immediately after the preparation of sealers (Fresh Group). In the second group, PDL cells were added after $24 \mathrm{~h}$, so that sealers were set ( $24 \mathrm{~h}$ Group). Five coverslips for each material per group were prepared. Each coverslip was placed on the bottom of a 24-well plate, $200 \mu \mathrm{l}$ of DMEM media was added in each well, and $2 \times 10^{4} \mathrm{PDL}$ cells were seeded on the polycarbonate filter with 
$30-\mu \mathrm{m}$ pores in the upper chamber of the transwells. A control medium was prepared in a similar manner but without materials. The cells were cultured for $72 \mathrm{~h}$ at $37^{\circ} \mathrm{C}$ in a $5 \% \mathrm{CO}_{2}$ humidified incubator. Finally, the cells were collected, trypsinized, stained with trypan blue, and counted using a hemocytometer.

\section{Statistical analysis}

Proliferation rate was not normally distributed. Consequently, Mann-Whitney U-test was used to compare the means of proliferation between Fresh and $24 \mathrm{~h}$ time points per sealer. In addition, Kruskal-Wallis test was applied for comparison between the measures of each material in Fresh and $24 \mathrm{~h}$ time points, and post hoc analysis with the use of Mann-Whitney test was performed for assessing the mean differences between each potential pair of materials. All reported probability values ( $P$ values) were compared to a significant level of $5 \%$. The analyses of coded data were carried out using IBMSPSS software version 21.0 (IBM Corporation, New York, USA).

\section{Cell morphology}

Different samples of the materials were shaped into $1 \mathrm{~mm}$ thick discs of $5 \mathrm{~mm}$ in diameter. Each specimen was placed in the bottom of the well of a 24-well culture plate. A volume of $300 \mu \mathrm{l}$ DMEM and $2.5 \times 10^{4}$ cells were added in each well. The cells were cultured for $72 \mathrm{~h}$ at $37^{\circ} \mathrm{C}$ in a $5 \% \mathrm{CO}_{2}$ humidified incubator.

The cells cultured on the surface of the samples were fixed in $4 \%$ PFA for 20 minatroom temperature, followed by PBS washing. The samples were then stained using Phalloidin-Rhodamin solution (Molecular Probes) to reveal the cytoskeleton and more specifically the actin filaments. 4',6-diamidino-2-phenylindole was used for the detection of the nucleus. To assess cell morphology related to the different endodontic sealers, samples were placed on top of a microscope slide with Vectashield (VECTOR Laboratories, Peterborough, UK) and observed under the confocal microscope Leica TCS SP5 (Leica, Wetzlar, Germany) in $\mathrm{a} \times 20$ resolution and analyzed using Leica software, LAS AF.

\section{RESULTS}

The mean values and standard deviation of viable cells for freshly mixed and $24 \mathrm{~h}$-set sealers are presented in Figure 1. The statistically significant differences among the groups are shown in Tables 1 and 2. Roth's 801, GuttaFlow 2, and Totalfill showed statistically significant differences $(P=0.008)$ in the number of

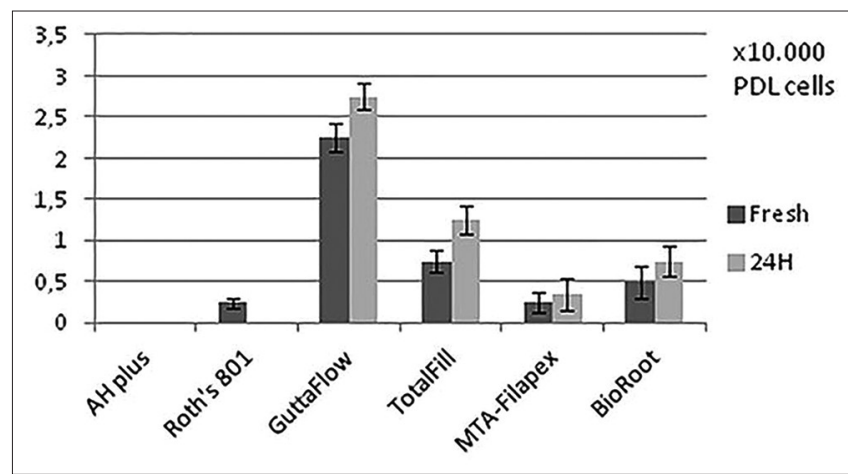

Figure 1: Mean values and standard deviations of periodontal ligament cells at freshly and $24 \mathrm{~h}$-set sealers

\begin{tabular}{lc}
$\begin{array}{l}\text { Table 1: Differences in cells proliferation between } \\
\text { freshly and } \mathbf{2 4} \text { h-setpoint time per sealer }\end{array}$ \\
\hline Sealer & $\boldsymbol{P}$ \\
\hline AH Plus & NS \\
Roth's 801 & 0.008 \\
GuttaFlow 2 & 0.008 \\
Totafill & 0.008 \\
MTA-Fillapex & NS \\
BioRoot & NS \\
\hline
\end{tabular}

Mann-Whitney U-test. NS: Not significant, MTA: Mineral trioxide aggregate

\begin{tabular}{lc}
$\begin{array}{l}\text { Table 2: Differences in cells proliferation between } \\
\text { sealers per time point }\end{array}$ \\
\hline Sealer & Fresh \\
\hline AH Plus versus Roth's 801 & 0.005 \\
AH Plus versus GuttaFlow 2 & 0.005 \\
AH Plus versus Totafill & 0.008 \\
AH Plus versus MTA-Fillapex & 0.008 \\
AH Plus versus BioRoot & 0.008 \\
Roth's 801 versus GuttaFlow 2 & 0.008 \\
Roth's 801 versus Totafill & 0.008 \\
Roth's 801 versus MTA-Fillapex & $\mathrm{NS}$ \\
Roth's 801 versus BioRoot & $\mathrm{NS}$ \\
GuttaFlow 2 versus Totafill & 0.008 \\
GuttaFlow 2 versus MTA-Fillapex & 0.008 \\
GuttaFlow 2 versus BioRoot & 0.008 \\
Totalfill versus MTA-Filapex & 0.008 \\
Totalfill versus BioRoot & $\mathrm{NS}$ \\
MTA-Fillapex versus BioRoot & $\mathrm{NS}$ \\
\hline NS: Not significant, MTA: Mineral trioxide aggregate &
\end{tabular}

NS: Not significant, MTA: Mineral trioxide aggregate

viable cells, between freshly and 24 h-set sealers [Table 1]. GuttaFlow 2, for both time points, presented the highest number of viable cells. The number of viable cells for MTA-Fillapex and BioRoot for the 24 h-set groups was higher than the freshly mixed, but not statistically significant [Table 1]. In addition, the comparison of sealers after their setting $(24 \mathrm{~h})$ shows statistically significant differences between them [Table 2]. All four novel endodontic sealers 
presented statistically significant higher number of viable cells in comparison to the convectional sealers for both time points, except for MTA-Fillapex and BioRoot, where in the freshly mixed group, there was no statistical significant difference.

Regarding the cell morphology alterations, cells grown on GuttaFlow 2 were observed to be well-formed, demonstrating a typical fibroblast-like, spindle-shaped, polarized morphology with elongated cytoskeleton with multiple thin processes [Figure 2a]. Similar morphology was also observed for Totalfill [Figure 2b], as well as BioRoot [Figure 2c], where stress fibers could be detected, and the cytoplasm was adequately stressed. On the contrary, MTA-Fillapex seemed to impinge on the cell distribution and morphology, as the cells appeared to abolish their spindle-shape appearance, becoming smaller and rounder in shape [Figure 2d]. No cells were detected on the surfaces of AH Plus, as well as Roth's 801.

\section{DISCUSSION}

In vitro investigations can provide useful information regarding the biological properties of new dental materials intended for clinical use. Such an experimental approach simplifies the system under study, so the researcher can focus on a small number of components and the evaluation of the cytotoxic potential of the materials may give an indication of the toxicity in the clinical setting. ${ }^{[19]}$ On the other hand, culture conditions are not homeostatic, and there is no eradication of toxic substances as there would be in vivo. Dissimilarly, the human body possesses a lymphatic system and periapical defenses such as polymorphonuclear leukocytes and macrophages to help remove toxic substances. ${ }^{[20]}$ These mechanisms


Figure 2: Cell morphology on the different endodontic sealers. (a) GuttaFlow 2, (b) TotalFill, (c) BioRoot, (d) mineral trioxide aggregate-Fillapex. No cells were detected on the surfaces of AH Plus, as well as Roth's 801 do not exist in a culture plate and should be a consideration for interpretations of the outcome of cell culture-based cytotoxicity studies reported in the literature.

In this study, an evaluation of cells viability in four novel endodontic sealers in comparison to two conventional sealers was performed, to simulate the root-end environment. PDL cells were exposed to sealers, immediately after their preparation as well as after $24 \mathrm{~h}$. These two-time points were selected because all conventional sealers reveal toxic effects when freshly mixed; but their toxicity is significantly reduced on setting. ${ }^{[21,22]}$ In our study, the aforementioned state was confirmed at almost all sealers. The number of cells that survived was higher at $24 \mathrm{~h}$ set materials than the freshly mixed in every sealer except Roth's 801 [Table 1]. When PDL cells were exposed to fresh Roth's 801 some of them, manage to survive, but when they were exposed to Roth's 801 after 24 h, no vital cells were detected. This is in accordance with the literature as previous studies have demonstrated that zinc oxide-eugenol sealers have presented noticeable cytotoxic and tissue-irrigating potencies in previous ex vivo cell culture studies. ${ }^{[22]}$ Some reports support that breakdown products from the sealers may have an adverse outcome on the proliferative capacity of periradicular cell populations. ${ }^{[23]}$

In our experimental setting, the most biocompatible sealer is GuttaFlow 2 in both time points. This sealer was also the only one that increased the initial cell number [Figure 1]. These findings correlate with the results of Willershausen et al. and Bouillaguet et al., that determine that the silicone-based sealer GuttaFlow is not cytotoxic and is considered to be biocompatible. ${ }^{[24,25]}$ Furthermore, according to Accardo et al., GuttaFlow 2 shows a similar biocompatibility profile as GuttaFlow. ${ }^{[8]}$

TotalFill BC Sealer presented the second highest number of viable cells at both time points [Figure 1]. This finding is in agreement with previous studies reporting that TotalFill BC Sealer displayed high biocompatibility with human fibroblasts after $24 \mathrm{~h}^{[26]}$ and is more biocompatible than MTA Fillapex and AH Plus. ${ }^{[17,27]}$

Regarding BioRoot, one of the newest sealers available in the dental market, it seems that it is more biocompatible than zinc-oxide eugenol sealers. ${ }^{[15,16]} \mathrm{In}$ our study, BioRoot presented a statistically significant higher number of viable cells than Roth's 801 among 
the 24 h group. MTA-Fillapex and BioRoot seem to demonstrate similar behavior, when they were freshly mixed or after $24 \mathrm{~h}$ [Table 2]. This is in agreement with a previous study, reporting that the cytotoxicity of MTA-Fillapex decreases after setting. ${ }^{[28]}$ Finally, AH Plus and Roth's 801 do not exhibit the biological properties of the others sealers which is in accordance with other studies. ${ }^{[29]}$

Confocal imaging revealed that PDL cells maintain their initial morphology when in contact with GuttaFlow 2, TotalFill, and BioRoot. This is an additional factor indicating their good biological properties. On the other hand, MTA-Fillapex seemed to impinge on the cell distribution and morphology, which is in accordance with its cells' proliferation rate. The low survivability of cells indicates that their morphology is also a result of sealer cytotoxicity. Furthermore, the loss of spindle-shaped appearance and their rounder shape probably burden their potential adhesion.

\section{CONCLUSIONS}

According to the results of this study, all novel endodontic sealers presented increased cell viability in comparison to conventional sealers such as $\mathrm{AH}$ plus and Roth's 801. GuttaFlow 2 exhibited the highest cell viability. Further investigations are required to validate the potential biological responses of those novel endodontic sealers.

\section{Financial support and sponsorship \\ Nil.}

\section{Conflicts of interest}

There are no conflicts of interest.

\section{REFERENCES}

1. Damas BA, Wheater MA, Bringas JS, Hoen MM. Cytotoxicity comparison of mineral trioxide aggregates and EndoSequence bioceramic root repair materials. J Endod 2011;37:372-5.

2. Gomes Cornélio AL, Salles LP, Campos da Paz M, Cirelli JA, Guerreiro-Tanomaru JM, Tanomaru Filho M, et al. Cytotoxicity of portland cement with different radiopacifying agents: A cell death study. J Endod 2011;37:203-10.

3. Geurtsen W, Leyhausen G. Biological aspects of root canal filling materials - Histocompatibility, cytotoxicity, and mutagenicity. Clin Oral Investig 1997;1:5-11.

4. Torabinejad M, Parirokh M. Mineral trioxide aggregate: A comprehensive literature review - Part II: Leakage and biocompatibility investigations. J Endod 2010;36:190-202.

5. Parirokh M, Torabinejad M. Mineral trioxide aggregate: A comprehensive literature review - Part I: Chemical, physical, and antibacterial properties. J Endod 2010;36:16-27.

6. Güven EP, Yalvaç ME, Kayahan MB, Sunay H, Şahın F, Bayirli G. Human tooth germ stem cell response to calcium-silicate based endodontic cements. J Appl Oral Sci 2013;21:351-357.

7. Gomes-Filho JE, Watanabe S, Lodi CS, Cintra LT, Nery MJ, Filho JA, et al. Rat tissue reaction to MTA FILLAPEX ${ }^{\circledR}$. Dent Traumatol 2012;28:452-6.

8. Accardo C, Himel VT, Lallier TE. A novel GuttaFlow sealer supports cell survival and attachment. J Endod 2014;40:231-4.

9. Zoufan K, Jiang J, Komabayashi T, Wang YH, Safavi KE, Zhu Q, et al. Cytotoxicity evaluation of gutta flow and endo sequence BC sealers. Oral Surg Oral Med Oral Pathol Oral Radiol Endod 2011;112:657-61.

10. Tyagi S, Mishra P, Tyagi P. Evolution of root canal sealers: An insight story. Eur J Gen Dent 2013;2:199-218.

11. Kontakiotis EG, Tzanetakis GN, Loizides AL. A comparative study of contact angles of four different root canal sealers. J Endod 2007;33:299-302.

12. Eldeniz AU, Mustafa K, Ørstavik D, Dahl JE. Cytotoxicity of new resin-, calcium hydroxide- and silicone-based root canal sealers on fibroblasts derived from human gingiva and L929 cell lines. Int Endod J 2007;40:329-37.

13. De-Deus G, Brandão MC, Fidel RA, Fidel SR. The sealing ability of GuttaFlow in oval-shaped canals: An ex vivo study using a polymicrobial leakage model. Int Endod J 2007;40:794-9.

14. Zhang H, Shen Y, Ruse ND, Haapasalo M. Antibacterial activity of endodontic sealers by modified direct contact test against Enterococcus faecalis. J Endod 2009;35:1051-5.

15. Dimitrova-Nakov S, Uzunoglu E, Ardila-Osorio H, Baudry A, Richard G, Kellermann O, et al. In vitro bioactivity of Bioroot ${ }^{\mathrm{TM}} \mathrm{RCS}$, via A4 mouse pulpal stem cells. Dent Mater 2015;31:1290-7.

16. Camps J, Jeanneau C, El Ayachi I, Laurent P, About I. Bioactivity of a calcium silicate-based endodontic cement (BioRoot RCS): Interactions with human periodontal ligament cells in vitro. J Endod 2015;41:1469-73.

17. Rodríguez-Lozano FJ, García-Bernal D, Oñate-Sánchez RE, Ortolani-Seltenerich PS, Forner L, Moraleda JM, et al. Evaluation of cytocompatibility of calcium silicate-based endodontic sealers and their effects on the biological responses of mesenchymal dental stem cells. Int Endod J 2017;50:67-76.

18. Konjhodzic-Prcic A, Jakupovic S, Hasic-Brankovic L, Vukovic A. In vitro comparison of cytotoxicity of four root canal sealers on human gingival fibroblasts. Med Arch 2015;69:24-7.

19. Luber-Narod J, Smith B, Grant W, Jimeno JM, López-Lázaro L, Faircloth GT, et al. Evaluation of the use of in vitro methodologies as tools for screening new compounds for potential in vivo toxicity. Toxicol In Vitro 2001;15:571-7.

20. Camps J, About I. Cytotoxicity testing of endodontic sealers: A new method. J Endod 2003;29:583-6.

21. Langeland K. Root canal sealants and pastes. Dent Clin North Am 1974;18:309-27.

22. Geurtsen W. Biocompatibility of root canal filling materials. Aust Endod J 2001;27:12-21.

23. Granchi D, Stea S, Ciapetti G, Cavedagna D, Stea S, Pizzoferrato A, et al. Endodontic cements induce alterations in the cell cycle of in vitro cultured osteoblasts. Oral Surg Oral Med Oral Pathol Oral Radiol Endod 1995;79:359-66.

24. Bouillaguet S, Wataha JC, Tay FR, Brackett MG, Lockwood PE. Initial in vitro biological response to contemporary endodontic sealers. J Endod 2006;32:989-92.

25. Willershausen I, Callaway A, Briseño B, Willershausen B. In vitro analysis of the cytotoxicity and the antimicrobial effect of four endodontic sealers. Head Face Med 2011;7:15.

26. Mukhtar-Fayyad D. Cytocompatibility of new bioceramic-based materials on human fibroblast cells (MRC-5). Oral Surg Oral Med Oral Pathol Oral Radiol Endod 2011;112:e137-42.

27. Zhou HM, Du TF, Shen Y, Wang ZJ, Zheng YF, Haapasalo M, et al. In vitro cytotoxicity of calcium silicate-containing endodontic sealers. J Endod 2015;41:56-61.

28. Salles LP, Gomes-Cornélio AL, Guimarães FC, Herrera BS, Bao SN, Rossa-Junior C, et al. Mineral trioxide aggregate-based endodontic sealer stimulates hydroxyapatite nucleation in human osteoblast-like cell culture. J Endod 2012;38:971-6.

29. Huang TH, Yang JJ, Li H, Kao CT. The biocompatibility evaluation of epoxy resin-based root canal sealers in vitro. Biomaterials 2002;23:77-83. 